\title{
Long-term treatment of residual or recurrent low-grade endometrial stromal sarcoma with aromatase inhibitors: A report of two cases and a review of the literature
}

\author{
HYEWON RYU, YOON-SEOK CHOI, IK-CHAN SONG, HWAN-JUNG YUN, \\ DEOG-YEON JO, SAMYONG KIM and HYO JIN LEE \\ Division of Hematology-Oncology, Department of Internal Medicine, Chungnam National University Hospital, \\ Daejeon 301-721, Republic of Korea
}

Received October 25, 2014; Accepted August 17, 2015

DOI: $10.3892 / 01.2015 .3674$

\begin{abstract}
Endometrial stromal sarcoma (ESS) occurs rarely and accounts for only $0.2 \%$ of all uterine malignancies. ESS usually expresses estrogen and progesterone receptors, and is regarded as hormone-sensitive. Due to the rarity of these tumors, there are only few case series on the use of aromatase inhibitors in the treatment of low-grade ESS. The present study reports the cases of two patients with residual or recurrent low-grade ESS who experienced long-term disease-free survival following treatment with letrozole. The study also reviews the literature with regard to the data on aromatase inhibitors used in patients with low-grade ESS. In total, 30 patients with recurrent or residual low-grade ESS who were treated with aromatase inhibitors were identified, including the present cases. Among the 30 patients, the overall response rate of advanced low-grade ESS to aromatase inhibitors was $77.4 \%$ (complete response, $25.8 \%$; partial response, $51.6 \%$ ) and the disease control rate was $90.3 \%$. The response rate of first-line treatment was similar to that of second-line therapy or higher (84.6 vs. $72.2 \%$; $\mathrm{P}=0.453)$. Duration of aromatase inhibitor treatment ranged from 1.5 to 168 months (median, 26.5 months). The aromatase inhibitors showed minimal adverse effects. In conclusion, aromatase inhibitors, particularly third-generation drugs, are a well-tolerated class of medications that are effective in the treatment of advanced low-grade ESS, with a favorable toxicity profile.
\end{abstract}

Correspondence to: Dr Hyo Jin Lee, Division of HematologyOncology, Department of Internal Medicine, Chungnam National Univeristy Hospital, 282 Munhwa-ro, Jung-gu, Daejeon 301-721, Republic of Korea

E-mail: cymed@cnu.ac.kr

Key words: endometrial stromal sarcoma, aromatase inhibitor, letrozole, anastrozole

\section{Introduction}

Uterine sarcomas are uncommon tumors, accounting for 2-3\% of all uterine neoplasms (1). Among the uterine sarcomas, endometrial stromal sarcoma (ESS) accounts for $10 \%$ of all tumors, representing $\sim 0.2 \%$ of all uterine malignancies, with an incidence of $\sim 2$ cases per million women per year (2). The tumors originate from the mesenchymal component of the endometrium and are characterized by a proliferation of cells with endometrial stromal (ES) cell differentiation. ESS is divided into low- and high-grade tumors according to cell morphology, mitotic rates, cellularity and the presence of necrosis. Recently, the term 'undifferentiated endometrial sarcoma' has been proposed for the World Health Organization classification of tumors instead of the term 'high-grade endometrial stromal sarcoma' due to the absence of original ES components in the tumor type $(3,4)$.

The initial treatment of choice for low-grade ESS is a hysterectomy with bilateral salpingo-oophorectomy. The role of adjuvant therapy, such as radiotherapy, chemotherapy or hormonal treatment, is not fully established (5). While the prognosis of low-grade ESS is favorable, with a 5-year overall survival of $>90 \%$, the recurrence-free survival rate is markedly lower at $\sim 50 \%(6,7)$.

Hormonal therapy, such as use of progestins (megestrol acetate and medroxyprogesterone acetate), has been used widely for advanced and recurrent ESS, as the majority of low-grade ESS express estrogen receptors (ERs) and progesterone receptors (PRs) (8). However, progestins can cause edema, weight gain, vaginal bleeding, hypertension and thromboembolic problems (9).

There are several anecdotal reports of low-grade ESS that responded to aromatase inhibitors, particularly the third generation of these drugs, with more favorable toxicity profiles and thus a wider therapeutic index $(6,9)$. However, due to the rarity of these tumors, there are no prospective or large retrospective studies on aromatase inhibitor use in the treatment of low-grade ESS. The present study reviewed the literature for data on aromatase inhibitor use in patients with low-grade ESS, including data from the present study on the cases of two patients with residual or recurrent low-grade ESS who 
experienced long-term disease-free survival following treatment with letrozole. All patients provided written informed consent to undergo therapy and publish the current case report.

\section{Case report}

Patient 1. A 51-year-old female, who presented to Chungnam National University Hospital (Daejeon, South Korea) with lower abdominal pain and vaginal bleeding, underwent a total abdominal hysterectomy with bilateral salpingo-oophorectomy in August 2007 for presumed adenomyosis. The final histology revealed a low-grade ESS of the uterus. The tumor immunostaining was strongly positive for ER and PR (ER: ++, 70\%; PR: +, 40\%). Positron emission tomography/computed tomography (CT) showed increased glucose metabolism at the small nodules in the presacral space, rectovaginal space and right common iliac lymph node. The patient received palliative chemotherapy, consisting of three cycles of paclitaxel $\left(175 \mathrm{mg} / \mathrm{m}^{2}\right)$ and cisplatin $\left(60 \mathrm{mg} / \mathrm{m}^{2}\right)$ between September and October 2007, but showed disease progression. In late November 2007, the patient underwent secondary debulking surgery, including a pelvic lymph node dissection, appendectomy, partial omentectomy and para-aortic lymph node dissection. In December 2007, the patient was referred to the Department of Internal Medicine for post-operative letrozole treatment, as follows. A baseline abdominopelvic CT scan revealed a small amount of ascites fluid and peritoneal seeding with an increased cancer antigen-125 (CA-125) level of $87.7 \mathrm{U} / \mathrm{ml}$ (normal range, 0-35 U/ml). The patient was started on letrozole at a daily dose of $2.5 \mathrm{mg}$. The CA-125 level normalized after 1 month of letrozole and a CT scan revealed a complete response (CR) after 3 months of the drug treatment. The patient has experienced a complete response to this therapy for 80 months, with no significant drug toxicity.

Patient 2. A 49-year-old female, who had known uterine myomas, visited Chungnam National University Hospital due to vaginal bleeding in August 2009. A magnetic resonance imaging scan of the pelvis revealed two large heterogeneous uterine masses. The patient underwent a total abdominal hysterectomy with bilateral salpingo-oophorectomy, pelvic lymph node dissection and para-aortic lymph node dissection for presumed uterine leiomyosarcoma. Histopathological examination revealed a low-grade ESS with tumor emboli in the periadnexal soft tissue. An immunohistochemical profile revealed positivity for ER $(++, 80 \%)$ and PR $(++, 80 \%)$ and the post-operative CA-125 level was $65.8 \mathrm{U} / \mathrm{ml}$. Between August and November 2009, the patient was prescribed medroxyprogesterone acetate at a daily dose of $1,000 \mathrm{mg}$. The CA-125 level was normalized after 2 months of this treatment, with no evidence of disease on abdominopelvic CT scans. However, the patient discontinued the medication 1 month later due to the adverse side-effects of weight gain and hypertension. The patient was then started on $2.5 \mathrm{mg}$ letrozole daily. The patient has experienced a CR for 57 months, with no adverse events.

\section{Literature review}

Method. For a systematic review, a search was performed of the English-language literature for reports of cases of low-grade
ESS treated with aromatase inhibitors. The systematic review was undertaken in MEDLINE/PubMed using the key words 'endometrial stromal sarcoma' combined with 'aromatase inhibitor.' Separate searches were then performed for 'uterine sarcoma', and 'endometrial sarcoma' combined with 'aromatase inhibitor'. The relevant studies were examined and reviewed, and any cited literature that had not been identified previously was also included and evaluated. Any patients with high-grade ESS were excluded. The primary outcome of this literature review was to evaluate the response rates of patients with low-grade ESS who were treated with aromatase inhibitors. The secondary outcomes included duration of aromatase inhibitor treatment. Treatment outcomes were defined as $\mathrm{CR}$, partial response (PR), stable disease (SD) or progressive disease (PD), based on the Response Evaluation Criteria In Solid Tumors (version 1.0) (10). Duration of aromatase treatment was defined as the interval from the date of initiation of aromatase inhibitor treatment to the date of discontinuation, mortality or last follow-up.

Statistical analysis. Categorical variables were analyzed using linear-by-linear association. For all analyses, $\mathrm{P}<0.05$ was considered to indicate a statistically significant difference. All statistical analyses were conducted using the SPSS software (version 17.0; SPSS Inc., Chicago, IL, USA).

Characteristics and treatment outcomes of patients treated with aromatase inhibitors. In total, 30 patients with recurrent or residual low-grade ESS, who were treated with aromatase inhibitors, including the 2 patients of the present study (patients 1 and 2), were identified. Table I shows the patient characteristics and treatment outcomes of those individuals with low-grade ESS who were treated with aromatase inhibitors (11-24). The age of the patients at the time of starting aromatase inhibitor treatment ranged from 28 to 87 years (mean age, 53 years). The duration of aromatase inhibitor treatment ranged from 1.5 to 168 months (median, 26.5 months). In total, 3 patients were administered more than one aromatase inhibitor (patients 5, 29 and 30). Of the 30 patients, 28 patient cases had the outcome recorded. The response rate to aromatase inhibitors in the evaluable patients is listed in Table II. The overall response rate to all aromatase inhibitors was $77.4 \%$ and the disease control rate was $90.3 \%$ if patients 5 , 29 and 30 are counted twice, once for each treatment $(n=31)$. A total of 8 patients (25.8\%) experienced a complete response, $16(51.6 \%)$ experienced a partial response, 4 (12.9\%) exhibited stable disease and $3(9.7 \%)$ experienced progressive disease. Among the aromatase inhibitors, letrozole was most widely used and appeared to be effective (overall response rate, 85.7\%). The association between response rate and the line of aromatase inhibitor treatment was also examined (Table III). The overall response rate of first-line aromatase inhibitor treatment $(11 / 13 ; 84.6 \%)$ was slightly higher than that of treatment with aromatase inhibitors of second-line or higher (13/18; 72.2\%), but the difference was not statistically significant $(\mathrm{P}=0.453)$. Aromatase inhibitors appear to be well tolerated, with a remarkably low incidence of side-effects. Only 2 patients experienced side-effects serious enough for discontinuation of the aromatase inhibitor. Patient 5 was treated with aminoglutethimide, a first-generation aromatase inhibitor, and suffered 
Table I. Characteristics and treatment outcomes of low-grade ESS patients treated with AIs.

\begin{tabular}{|c|c|c|c|c|c|c|c|}
\hline $\begin{array}{l}\text { Patient } \\
\text { no. (ref) }\end{array}$ & $\begin{array}{l}\text { Age, } \\
\text { years }^{\text {a }}\end{array}$ & $\begin{array}{l}\text { Systemic therapy } \\
\text { prior to AI }\end{array}$ & $\mathrm{ER} / \mathrm{PR}$ & AI & $\begin{array}{l}\text { Response } \\
\text { to AI }\end{array}$ & $\begin{array}{l}\text { Duration of } \\
\text { AI, months }\end{array}$ & Status ${ }^{\mathrm{b}}$ \\
\hline 1 & 51 & $\mathrm{PC}$ & $+/+$ & Letrozole & $\mathrm{CR}$ & $77+$ & NED \\
\hline 2 & 49 & & $+/+$ & Letrozole & $\mathrm{CR}$ & $55+$ & NED \\
\hline $3(11)$ & 58 & Tamoxifen, MA & $+/+$ & Letrozole & PR & 9 & AWD \\
\hline $4(12)$ & 47 & & $+/+$ & Aminoglutethimide & $\mathrm{CR}$ & $168+$ & NED \\
\hline $5(12)$ & 40 & Tamoxifen & $+/+$ & $\begin{array}{l}\text { Aminoglutethimide } \\
\rightarrow \text { Letrozole }\end{array}$ & $\begin{array}{l}\mathrm{PR} \\
\mathrm{CR}\end{array}$ & $\begin{array}{l}39 \\
43+\end{array}$ & NED \\
\hline $6(13)$ & 76 & & $+/+$ & Letrozole & PR & $36+$ & AWD \\
\hline $7(14)$ & 51 & BEP, DG & $+/+$ & Anastrozole with MA & PR & $24+$ & AWD \\
\hline $8(6)$ & 63 & MPA & $+/+$ & Letrozole & PR & $37+$ & AWD \\
\hline $9(6)$ & 69 & & $+/+$ & Letrozole & PR & $9+$ & AWD \\
\hline $10(6)$ & 42 & & $+/+$ & Letrozole & PR & $10+$ & AWD \\
\hline $11(6)$ & 69 & & $+/+$ & Letrozole & PD & na & AWD \\
\hline $12(6)$ & 47 & Tamoxifen & $+/+$ & Letrozole & PR & $3+$ & AWD \\
\hline $13(15)$ & 56 & & $+/+$ & Letrozole & $\mathrm{CR}$ & $24+$ & AWD \\
\hline $14(16)$ & 61 & $\begin{array}{c}\text { Tamoxifen, etoposide, } \\
\text { progestin }\end{array}$ & na & ns & na & na & AWD \\
\hline $15(16)$ & 65 & Etoposide & na & ns & na & na & AWD \\
\hline $16(17)$ & 48 & & $+/+$ & Letrozole & PR & $39+$ & AWD \\
\hline $17(18)$ & 41 & Goserelin & $+/+$ & Anastrozole & $\mathrm{CR}$ & $108+$ & AWD \\
\hline $18(19)$ & 49 & MA & na & Letrozole & PR & $29+$ & NED \\
\hline $19(20)$ & 87 & & na & Letrozole & PD & na & AWD \\
\hline $20(20)$ & 53 & & na & Letrozole & PR & $4+$ & AWD \\
\hline $21(20)$ & 47 & MA & $-/-$ & Letrozole & PR & $6+$ & AWD \\
\hline $22(21)$ & na & & $+/+$ & Letrozole & $\mathrm{CR}$ & 88 & na \\
\hline $23(21)$ & na & MA & $+/+$ & Letrozole & PR & $124^{\mathrm{c}}$ & na \\
\hline $24(21)$ & na & & na & Letrozole & PR & 53 & na \\
\hline $25(22)$ & 59 & & $+/+$ & Letrozole & $\mathrm{CR}$ & $24+$ & NED \\
\hline $26(23)$ & 53 & MPA & $+/+$ & Anastrozole & PR & 9 & AWD \\
\hline $27(24)$ & 28 & MA & $+/-$ & Anastrozole & SD & $70+$ & AWD \\
\hline $28(24)$ & 37 & MA & $+/+$ & Anastrozole & SD & na & AWD \\
\hline $29(24)$ & 42 & MA & $? /+$ & $\begin{array}{l}\text { Anastrozole } \\
\rightarrow \text { Exemestane }\end{array}$ & $\begin{array}{l}\text { PD } \\
\text { PR }\end{array}$ & $\begin{array}{l}1.5 \\
6+\end{array}$ & AWD \\
\hline $30(24)$ & 44 & MA & na & $\begin{array}{l}\text { Anastrozole } \\
\rightarrow \text { Letrozole }\end{array}$ & $\begin{array}{l}\text { SD } \\
\text { SD }\end{array}$ & $\begin{array}{l}16 \\
10+\end{array}$ & AWD \\
\hline
\end{tabular}

${ }^{a}$ Estimated age at the time of starting aromatase inhibitor treatment. ${ }^{b}$ Patient's status when the case was reported. 'Includes duration of response to megesterol. Letrozole was administered at $2.5 \mathrm{mg}$ daily; aminoglutethimide was administered at $500 \mathrm{mg}$ four times a day; anastrozole was administered at $1 \mathrm{mg}$ daily; and exemestane was administered at $25 \mathrm{mg}$ daily. Patient 4: Initial aminoglutethimide was discontinued according to the patient's decision following the achievement of a CR. Low-grade ESS recurrence was observed, and following luteinizing hormone-releasing hormone analog use, the initial treatment was restarted and a CR was achieved once again. Patient 5: Aminoglutethimide was discontinued due to treatment side-effects (asthenia and diarrhea) after 39 months of PR and then letrozole was started, resulting in a CR. Patient 7 was diagnosed with ESS with a sex-cord stromal component at the time of hysterectomy. Patient 18 underwent an anterior exenteration with negative margins, resulting in a CR. Patient 21 was diagnosed with a mix of low-grade ESS and undifferentiated sarcoma. Patient 26 underwent a complete resection of the recurrent tumor following a PR to anastrozole treatment for 9 months and subsequently remained progression-free for 16 months. AI, aromatase inhibitor; ER, estrogen receptor; PR, progesterone receptor; CR, complete response; PR, partial response; SD, stable disease; PD, progression; NED, no evidence of disease; AWD, alive with disease; PC, paclitaxel and cisplatin regimen; BEP, bleomycin, etoposide and cisplatin regimen; DG, docetaxel and gemcitabine regimen; MPA, medroxyprogesterone acetate; MA, megestrol acetate; na, not available; ns, not specified; $\rightarrow$, second treatment.

from asthenia and diarrhea. However, the patient showed a CR without side-effects over a long period once prescribed letrozole, a third-generation aromatase inhibitor. Patient 26, who was treated with anastrozole for 9 months, experienced arthritis with joint dysfunction and discontinued use of the drug. 
Table II. Response rate to AI in evaluable patients with low-grade endometrial stromal sarcoma.

\begin{tabular}{lcccc}
\hline & \multicolumn{3}{c}{ AI } \\
\cline { 2 - 5 } $\begin{array}{l}\text { Best } \\
\text { response }\end{array}$ & $\begin{array}{c}\text { All, }(\%) \\
(\mathrm{n}=31)^{\mathrm{a}}\end{array}$ & $\begin{array}{c}\text { Aminoglutethimide } \\
(\mathrm{n}=2)\end{array}$ & $\begin{array}{c}\text { Letrozole } \\
(\mathrm{n}=21)\end{array}$ & $\begin{array}{c}\text { Anastrozole } \\
(\mathrm{n}=7)\end{array}$ \\
\hline $\mathrm{CR}$ & $8(25.8)$ & 1 & 6 & 1 \\
$\mathrm{PR}$ & $16(51.6)$ & 1 & 12 & 2 \\
$\mathrm{SD}$ & $4(12.9)$ & & 1 & 3 \\
$\mathrm{PD}$ & $3(9.7)$ & & 2 & 1 \\
\hline
\end{tabular}

${ }^{\mathrm{a} C}$ Counting patients 5,29 and 30 twice, once for each treatment. AI, aromatase inhibitor; CR, complete response; PR, partial response; $\mathrm{SD}$, stable disease; PD, progressive disease.

Table III. Response rate to first-line $(n=13)$ and second-line or higher $(\mathrm{n}=18)$ AIs in evaluable patients with low-grade endometrial stromal sarcoma.

\begin{tabular}{llcr}
\hline & \multicolumn{2}{c}{ AI } & \\
\cline { 2 - 3 } $\begin{array}{l}\text { Best } \\
\text { response }\end{array}$ & $\begin{array}{c}\text { First-line, } \\
\mathrm{n}(\%)\end{array}$ & $\begin{array}{c}\text { Second-line or } \\
\text { higher, n (\%) }\end{array}$ & P-value \\
\hline CR & $5(38.5)$ & $3(16.7)$ & 0.453 \\
PR & $6(46.2)$ & $10(55.6)$ & \\
SD & $0(0.0)$ & $4(22.2)$ & \\
PD & $2(15.4)$ & $1(5.6)$ & \\
\hline
\end{tabular}

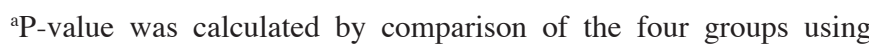
linear-by-linear associations. CR, complete response; PR, partial response; $\mathrm{SD}$, stable disease; $\mathrm{PD}$, progressive disease.

\section{Discussion}

ESSs are rare tumors that occur predominantly in premenopausal and perimenopausal women (25-27). ESSs are indolent tumors and have long disease-free intervals in the absence of specific therapies, such as estrogen-containing hormone replacement therapy or tamoxifen. The prognosis for low-grade ESS is extremely good, with a 5-year survival rate of $>90 \%$ (6). However, $40-50 \%$ of those individuals with low-grade ESS develop recurrent disease, which often occurs 10-20 years after the initial diagnosis $(17,18)$.

ESS resembles proliferating endometrial stroma histologically, typically expressing ERs and PRs, and is regarded as hormone-sensitive. Aromatase inhibitors, progesterone and gonadotropin-releasing hormone agonists have all been suggested as uterine sarcoma treatments. Progestins are the most widely used agents for the treatment of advanced and recurrent ESS (8). Progestins inhibit estrogen-mediated growth factors, downregulate the ER and increase estrogen metabolism and clearance, thereby decreasing the effects of estrogen on ER-positive cells. Although progestins are an effective medication, they also exhibit various adverse side-effects, including weight gain, depression and thromboembolic events (9).
Aromatase inhibitors have been used in the treatment of breast cancer and are a potential treatment for ESS. Aromatase inhibitors decrease levels of estrogen by peripherally inhibiting estrogen synthesis. First-generation (aminoglutethimide) and second-generation (formestan and fadrozole) aromatase inhibitors were non-specific non-steroidal aromatase inhibitors, which exhibited serious side-effects due to the inhibition of mineralocorticoid and glucocorticoid synthesis (9). The third-generation non-steroidal aromatase inhibitors exemestane and letrozole, and the steroidal aromatase inhibitor anastrozole, exhibit minimal effects on the adrenal glands and can be orally administered. Several case studies have been published with regard to the efficacy of the aromatase inhibitors aminoglutethimide, letrozole, anastrozole and exemestane in the treatment of advanced low-grade ESS $(20,27)$. However, no systemic systematic reviews or prospective studies on aromatase inhibitor treatment for ESS have been published. In the literature review of aromatase inhibitor treatment in patients with low-grade ESS in the present study, the overall response rate was $77.4 \%$ and the disease control rate was $90.3 \%$. Additionally, aromatase inhibitors showed similar tumor responses in the second-line or higher treatment setting compared with first-line therapy. Furthermore, aromatase inhibitors, particularly third-generation letrozole, which is the most widely used aromatase inihibitor, are well tolerated during long-term treatment. Together, these data suggest that aromatase inhibitors are effective for the treatment of low-grade ESS and exhibit a favorable toxicity profile.

The present study reports the cases of two patients with residual or recurrent low-grade ESS who experienced long-term disease-free survival following treatment with letrozole. Aromatase inhibitors, particularly the third-generation drugs, are a well-tolerated class of medications that are effective for the treatment of ESS with minimal adverse effects and thus a higher therapeutic window. However, given the rarity of these tumors, data from large, prospective randomized trials are lacking. To address these issues, a large, multicenter, prospective trial is required.

\section{References}

1. Olah KS, Gee H, Blunt S, Dunn JA, Kelly K and Chan KK: Retrospective analysis of 318 cases of uterine sarcoma. Eur J Cancer 27: 1095-1099, 1991. 
2. Harlow BL, Weiss NS and Lofton S: The epidemiology of sarcomas of the uterus. J Natl Cancer Inst 76: 399-402, 1986.

3. Evans HL: Endometrial stromal sarcoma and poorly differentiated endometrial sarcoma. Cancer 50: 2170-2182, 1982.

4. Amant F, Vergote I and Moerman P: The classification of a uterine sarcoma as 'high-grade endometrial stromal sarcoma' should be abandoned. Gynecol Oncol 95: 412-413, author reply 413, 2004.

5. Reich $\mathrm{O}$ and Regauer S: Survey of adjuvant hormone therapy in patients after endometrial stromal sarcoma. Eur J Gynaecol Oncol 27: 150-152, 2006

6. Pink D, LindnerT, Mrozek A, Kretzschmar A, Thuss-Patience PC Dörken B and Reichardt P: Harm or benefit of hormonal treatment in metastatic low-grade endometrial stromal sarcoma: Single center experience with 10 cases and review of the literature. Gynecol Oncol 101: 464-469, 2006.

7. Ashraf-Ganjoei T, Behtash N, Shariat M and Mosavi A Low grade endometrial stromal sarcoma of uterine corpus, a clinico-pathological and survey study in 14 cases. World J Surg Oncol 4: 50, 2006

8. Amant F, Moerman P, Cadron I, Neven P, Berteloot P and Vergote I: The diagnostic problem of endometrial stromal sarcoma: Report on six cases. Gynecol Oncol 90: 37-43, 2003.

9. Reich $\mathrm{O}$ and Regauer S: Hormonal therapy of endometrial stromal sarcoma. Curr Opin Oncol 19: 347-352, 2007.

10. Therasse P, Arbuck SG, Eisenhauer EA, Wanders J, Kaplan RS, Rubinstein L, Verweij J, Van Glabbeke M, van Oosterom AT, Christian MC and Gwyther SG. New guidelines to evaluate the response to treatment in solid tumors. European Organization for Research and Treatment of Cancer, National Cancer Institute of the United States, National Cancer Institute of Canada. J Natl Cancer Inst 92: 205-216, 2000

11. Maluf FC, Sabbatini P, Schwartz L, Xia J and Aghajanian C: Endometrial stromal sarcoma: Objective response to letrozole. Gynecol Oncol 82: 384-388, 2001.

12. Spano JP, Soria JC, Kambouchner M, Piperno-Neuman S, Morin F, Morere JF, Martin A and Breau JL: Long-term survival of patients given hormonal therapy for metastatic endometrial stromal sarcoma. Med Oncol 20: 87-93, 2003.

13. Leunen M, Breugelmans M, De Sutter P, Bourgain C and Amy JJ: Low-grade endometrial stromal sarcoma treated with the aromatase inhibitor letrozole. Gynecol Oncol 95: 769-771, 2004.

14. Leiser AL, Hamid AM and Blanchard R: Recurrence of prolactin-producing endometrial stromal sarcoma with sex-cord stromal component treated with progestin and aromatase inhibitor. Gynecol Oncol 94: 567-571, 2004.

15. Brechot JM, Kamboucher M, Brauner M, Destable M, Duperron F and Morère JF: Pulmonary metastases from endometrial stroma sarcoma may benefit from hormone therapy. Rev Mal Respir 24 69-72, 2007 (In French).
16. Landréat V, Paillocher N, Catala L, Foucher F, Descamps P and Levêque J: Low-grade endometrial stromal sarcoma of the uterus: Review of 10 cases. Anticancer Res 28: 2869-2874, 2008.

17. Krauss K, Bachmann C, Hartmann JT, Siegmann K, Sotlar K, Wallwiener D and Huober J: Management of late recurrence of a low-grade endometrial stromal sarcoma (LGESS): Treatment with letrozole. Anticancer Res 27: 3477-3480, 2007.

18. Alkasi O, Meinhold-Heerlein I, Zaki R, Fasching P, Maass N, Jonat W and Beckmann MW: Long-term disease-free survival after hormonal therapy of a patient with recurrent low grade endometrial stromal sarcoma: A case report. Arch Gynecol Obstet 279: 57-60, 2009.

19. Tzakas E, Liu S, Todd RW and Redman CW: Hormonal therapy with letrozole prior to surgical management of recurrent metastatic low-grade endometrial stromal sarcoma (LGESS). J Obstet Gynaecol 29: 778-779, 2009.

20. Dahhan T, Fons G, Buist MR, Ten Kate FJ and van der Velden J: The efficacy of hormonal treatment for residual or recurrent low-grade endometrial stromal sarcoma. A retrospective study. Eur J Obstet Gynecol Reprod Biol 144: 80-84, 2009.

21. Ioffe YJ, Li AJ, Walsh CS, Karlan BY, Leuchter R, Forscher C and Cass I: Hormone receptor expression in uterine sarcomas: Prognostic and therapeutic roles. Gynecol Oncol 115: 466-471, 2009.

22. Sylvestre VT and Dunton CJ: Treatment of recurrent endometrial stromal sarcoma with letrozole: A case report and literature review. Horm Cancer 1: 112-115, 2010.

23. Shoji K, Oda K, Nakagawa S, Kawana K, Yasugi T, Ikeda Y, Takazawa Y, Kozuma S and Taketani Y: Aromatase inhibitor anastrozole as a second-line hormonal treatment to a recurrent low-grade endometrial stromal sarcoma: A case report. Med Oncol 28: 771-774, 2011.

24. Altman AD, Nelson GS, Chu P, Nation J and Ghatage P: Uterine sarcoma and aromatase inhibitors: Tom baker cancer centre experience and review of the literature. Int J Gynecol Cancer 22: 1006-1012, 2012.

25. Balleine RL, Earls PJ, Webster LR, Mote PA, deFazio A, Harnett PR and Clarke CL: Expression of progesterone receptor $\mathrm{A}$ and $\mathrm{B}$ isoforms in low-grade endometrial stromal sarcoma. Int J Gynecol Pathol 23: 138-144, 2004.

26. Chu MC, Mor G, Lim C, Zheng W, Parkash V and Schwartz PE: Low-grade endometrial stromal sarcoma: Hormonal aspects. Gynecol Oncol 90: 170-176, 2003.

27. Reich O, Regauer S, Urdl W, Lahousen M and Winter R: Expression of oestrogen and progesterone receptors in low-grade endometrial stromal sarcomas. Br J Cancer 82: 1030-1034, 2000. 